\title{
Tweaking homogeneity and stability of gold nanorods by synergistic action of $\mathrm{pH}$ and temperature
}

\author{
Nitin Kumar, Shivesh Sharma and Seema Nara* \\ Department of Biotechnology, Motilal Nehru National Institute of Technology Allahabad 211004, U.P. India \\ *Corresponding author
}

DOI: $10.5185 / \mathrm{amp} .2018 / 7005$

www.vbripress.com/amp

\begin{abstract}
Commonly used seed-mediated method of gold nanorod synthesis has limitations like formation of by-products (stars, squares, dog-bones, platelets), slow but continuous growth during storage/ageing which adversely affects their homogeneity. Storage in the presence of cetyltrimethylammonium bromide (CTAB) is also essential to prevent their aggregation, which being toxic, needs to be removed before using them for biological applications. We herein, present a simple approach to overcome these limitations through synergistic action of low $\mathrm{pH}$ and high temperature. The proposed modifications synthesize highly homogeneous nanorods which are stable upto months even when stored in water. Copyright @ 2018 VBRI Press.
\end{abstract}

Keywords: By-products, gold nanorods, homogenity, seed-mediated, stability.

\section{Introduction}

During early period nanotechnology was focused on the synthesis methods related to spherical particles only, though different shapes of particles like stars, cubes, rods and shells are now easily prepared [1-3]. Recently studies on gold nanorods (GNRs) have caught the pace. Unique optical properties [4], tunable aspect ratio, superior absorption cross section at near infra-red frequencies and manifold higher detection efficiency [5] makes GNRs ideal candidate for diagnostics, biosensing, and photodynamic therapy applications. Low aspect ratio GNRs are more promising for these applications. Methods for synthesis of GNR includes template based synthesis [6], photochemical [7], electrochemical methods [8], wet-chemical synthesis [9], and seed mediated synthesis [10]. The state-of-art seed mediated nanorod synthesis method introduced by Busbee et al., (2003) [11] and improved by Nikoobakht and Sayed (2003) [6] has attained wide spread attention. But GNRs synthesized using this protocol are generally cetyltrimethylammonium bromide (CTAB)protected and when suspended in organic media they instantly get aggregated [12]. Also this method uses ascorbic acid as reducing agent and it makes growth of GNRs hard to control which cause the appearance of few non-rod like structures like spheres, stars, platelets and cubic particles [13]. Despite various studies on controlling the aspect ratio of nanorods in seed mediated synthesis, control over shape and size still remains a challenging task. Increased homogeneity in shape and size of nanorods has been achieved by replacing citrate with cetyltrimethylammonium bromide (CTAB) [1] and by manipulating the concentrations of silver nitrate, ascorbic acid and gold ( $\mathrm{Au})$ to seed ratio, which minimizes formation of spherical nanoparticles $(<1 \%)$ [1]. However, with suppression of spherical nanoparticles various by-products like stars, squares, triangles, platelets and dogbone shape nanorods arises $[1,6,14-16]$; in line with our own experience. The importance of $\mathrm{pH}$ of reaction medium in controlling the shape of nanorods is also observed by some groups. Differently shaped (dogbones, peanut, multipodes or ill shaped) structures appears from $\mathrm{pH} 3.6$ and above. This is evident from the sensitive LSPR peak which losses it's typical, guassian shape with increasing $\mathrm{pH}$ indicating disappearance of nanorods with increase in sphericity of nanoparticles [17]. Maintaining $\mathrm{pH}<3.0$ with $\mathrm{HCl}$ or glycine buffer tend to produce nanorods with aspect ratio 2.2-2.8 [17-18], whereas use of $\mathrm{HNO}_{3}$ tend to increase the aspect ratio to $14-16[19] . \mathrm{HCl}$ treated nanorods are reported to be stable but the possibility of side-by-side assembly of $\mathrm{HCl}$ treated nanorods could not be completely excluded [18] leading to a minor blue shift in Local Surface Plasmon Resonance (LSPR). Use of $\mathrm{H}_{2} \mathrm{SO}_{4}$ in growth solution reduces the rate of GNRs formation [12].

Temperature of reaction medium is also debatable as changing temperature leads to change in aspect ratio of nanorods. Nanorod synthesis is reported to be favourable at room temperature or temperatures below $50^{\circ} \mathrm{C}$ in a seed mediated approach as CTAB micelles 
break down at high temperatures [20-21]. However, high temperature (up to $97^{\circ} \mathrm{C}$ ) synthesis of nanorods is also reported in a seedless synthesis approach [12]. Aspect ratio of nanorods is reported to decrease with increasing temperature [23-24]. Becker et al has recently reported most homogeneous morphology at low temperature $\left(25^{\circ} \mathrm{C}\right)$ and presence of non-rod shaped particle at high temperatures [25]. This is contradictory to our findings in the manuscript. The problem of shape heterogeneity still persists with seed mediated method and quest for optimum reaction conditions is still on. Another issue associated with seed mediated GNR synthesis is slow temporal evolution of nanorods, sometimes also referred as "ageing". Nanorods keep on growing at room temperature as evidenced by their changing length-width or aspect ratio which can be monitored spectrometrically. Surface of the nanorods becomes smooth during ageing with transition from a broader absorption peak to a sharp and narrow peak [17]. But, continuous growth during storage can lead to batch-to-batch variation in nanorods due to lack of control over shape during ageing phenomenon. Minimizing the ageing period or exercising more control over growing nanorods during ageing without compromising with shape and stability needs to be tactfully addressed. A probable reason for less homogeneity and control over growth during ageing is the presence of unconsumed reactants and their slow but continuous addition over the growing facets of nanorods. In this article, we try to address the problems raised above through synergistic effect of low $\mathrm{pH}$ and high temperature. Effect of $\mathrm{pH}$ or temperature on nanorod synthesis has been studied separately by different groups but the impact of combining these two parameters on nanorod quality and stability has not been investigated. The basic principle behind this approach is to eliminate excess free $\mathrm{CTAB}$ from the solution with low $\mathrm{pH}$ and to increase the reaction rate with high temperature. This probably allows complete consumption of reactants and restricts amount of excess $\mathrm{CTAB}$ for further growth of nanorods. Also, any alteration in $\mathrm{pH}$ or temperature is usually done before the addition of seed solution to growth solution or when the growth solution is fully matured. All these explorations with reagents and their time of addition can give opportunity for limitless variation in GNRs synthesis [26]. We also tried to find out the appropriate time or step during the course of reaction at which these parameters shall be modulated.

\section{Experimental}

\section{Materials / chemicals details}

All reagents and chemicals were of analytical grade. Cetyl Trimethylammonium Bromide (CTAB), Chloroauric acid $\left(\mathrm{HAuCl}_{4}\right)$, sodium borohydrate $\left(\mathrm{NaBH}_{4}\right)$, ascorbic acid, silver nitrate was obtained from Sigma Aldrich, USA. Experiments were performed in Milli-Q water (18M $\Omega)$.

\section{Material synthesis / reactions}

Synthesis of nanorods: Gold nanorods in aqueous solution were synthesized by a typical seedmediated, Ag (I)-assisted growth method described in the literature [6]. Briefly, following method was performed.

Preparation of the seed: Firstly, an aqueous seed solution was prepared. $5 \mathrm{~mL}$ of $\mathrm{HAuCl}_{4}(0.5 \mathrm{mM})$ was added to $5 \mathrm{~mL}$ of $\mathrm{CTAB}$ solution $(0.2 \mathrm{M})$ by constant stirring at $25^{\circ} \mathrm{C}$, then $0.6 \mathrm{~mL}$ ice-cold $\mathrm{NaBH}_{4}$ $(0.01 \mathrm{M})$ was added with vigorous stirring, which resulted in a color change from yellow to brownishyellow. The obtained solution was stirred for another $2 \mathrm{~min}$ at $25^{\circ} \mathrm{C}$ and used as the seed solution. This solution was kept at $25^{\circ} \mathrm{C}$ and was used for nanorod synthesis within $2 \mathrm{~h}$.

Preparation of the growth solution: Gold nanorods were prepared using an aqueous growth solution of 5 mL CTAB $(0.2 \mathrm{M})$. To this solution, $0.15 \mathrm{ml}$ of $4 \mathrm{mM}$ $\mathrm{AgNO}_{3}$ was added with gentle stirring at $28^{\circ} \mathrm{C}$, followed by $5 \mathrm{~mL}$ of $1 \mathrm{mM} \mathrm{HAuCl} 4$. After gentle mixing of the solution by stirring for several seconds, $70 \mu \mathrm{l}$ of $78.8 \mathrm{mM}$ ascorbic acid was added, and after vigorous stirring for $2 \mathrm{~min}$ the color of the solution changed from dark yellow to colorless. Finally, $12 \mu 1$ of seed solution was then added to the growth solution and stirred for $20 \mathrm{~s}$ at $28^{\circ} \mathrm{C}$. The solution was allowed to mature by incubating overnight at $28^{\circ} \mathrm{C}$ and subsequently used for analysis.

\section{Characterizations}

GNRs were characterized on Oxford Energy dispersive spectroscopy system for Energy Dispersive Spectroscopy (EDX) compositional analysis. For crystal structure XRD-analysis, Rikaku-Smart lab X-ray diffractometer was used at $40 \mathrm{kV}, 30$ amperes and $1.4 \mathrm{~A}^{\circ} \mathrm{X}$-ray wavelength. UV-vis spectroscopy to evaluate nanorod integrity. All UV-vis spectra were measured by CARRY60 UV-Vis spectrophotometer (Agilent Technologies). Transmission electron microscopy (TEM) characterizations were done on a HITACHI (H-7500) transmission electron microscope with a $120 \mathrm{kV}$ operating voltage. Nanorod samples were drop and casted on TEM grids and dried overnight before imaging.

\section{Results and discussion}

Gold nanorods are synthesized using well established seed mediated approach of Nikoobakht and Sayed (2003) [6] without any deviation in the standard protocol and characterized by EDX (Fig. 1(a)) XRD (Fig. 1(b)), UV-Vis spectroscopy and TEM. Fig. 2 shows the illustration of the proposed work. Nanorod solution was allowed to fully mature by overnight incubation at $28^{\circ} \mathrm{C}$. Fig.3 (a) shows the UV-Vis spectra of this fully matured nanorod dispersion which we refer to as "control" in the manuscript. In addition to the 


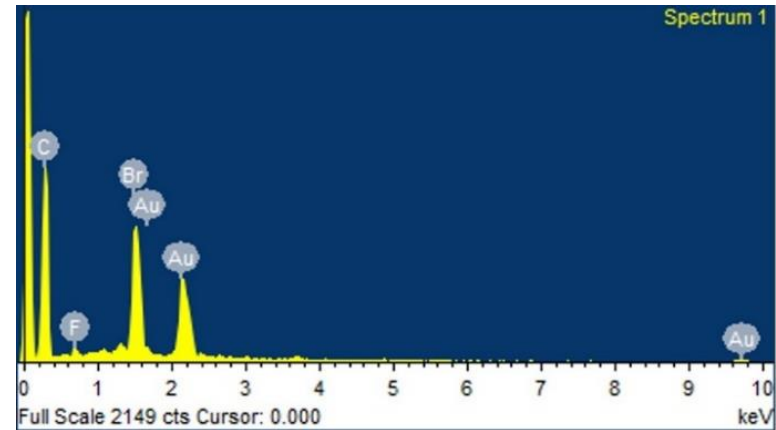

a)

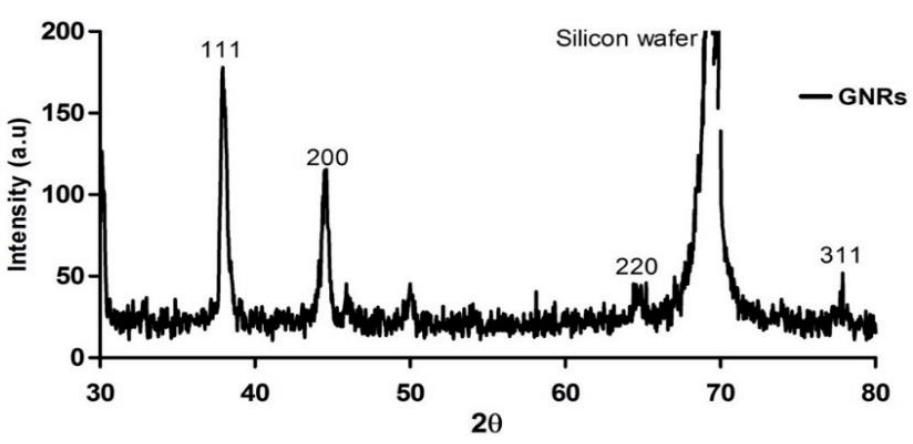

b)

Fig. 1. EDX and X-Ray diffraction spectra of Gold nanorods.

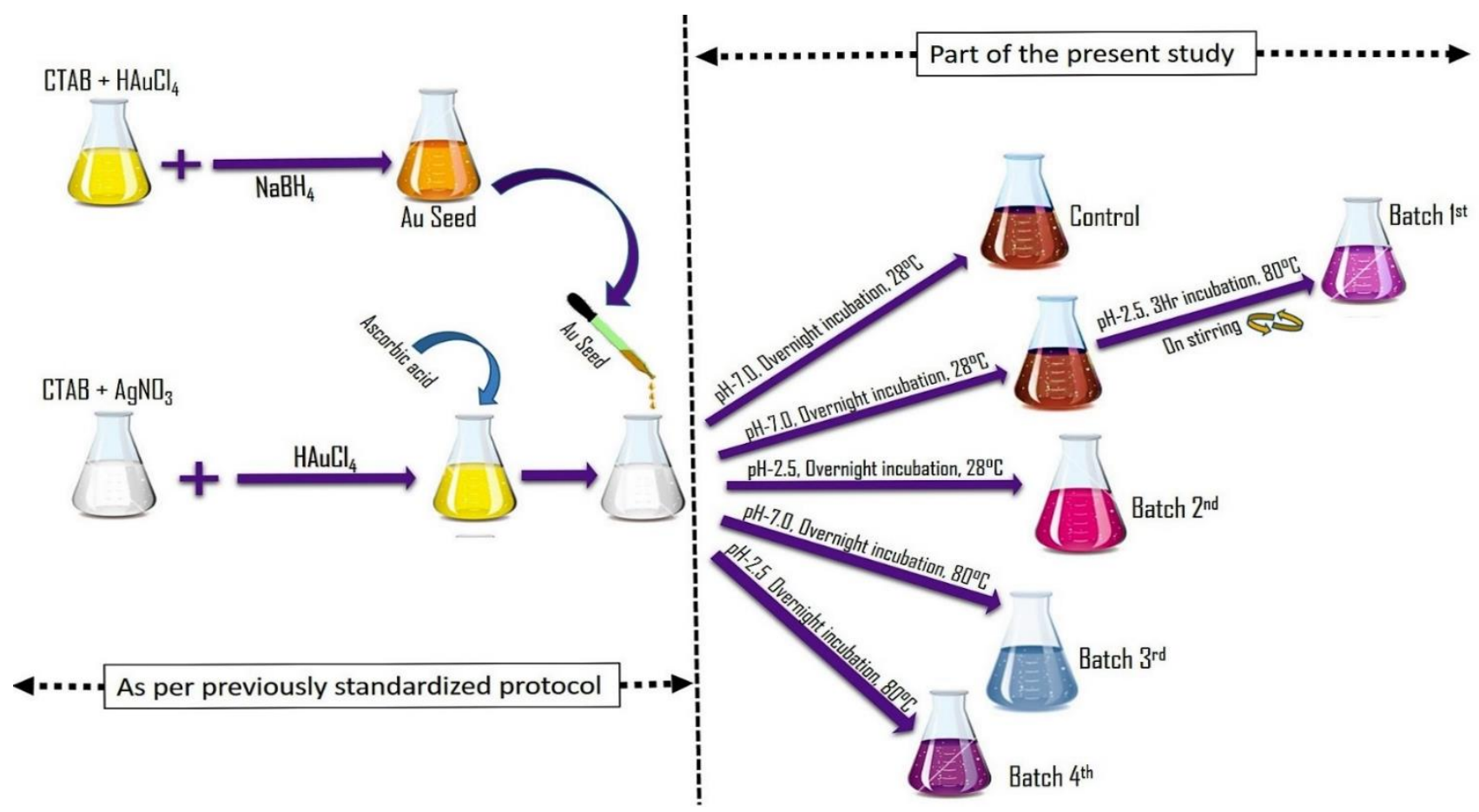

Fig. 2. Illustration of the designed synthesis processes of Gold nanorods.

characteristic transverse and longitudinal peaks, a third peak appears as shoulder near 630nm. Fig. 3 (b) shows the transmission electron microscopy (TEM) graphs of these nanorods. It depicts the presence of by-products or debris like triangles, squares, platelets and dogbone shaped GNRs. This synthesis has been performed several times to overrule the possibility of any error in the protocol leading to by-product formation. We credit the third peak near $630 \mathrm{~nm}$ to these by-products. Further, it is observed that these GNRs aggregate faster at room temperature (data not shown). In order to get rid of these reaction by-products and to stop aggregation of nanorods, reaction conditions are modified. Lowering the $\mathrm{pH}$ of mature GNR solution followed by heating has been shown to increase their stability and surface enhanced raman scattering (SERS) performance [17]. We therefore synthesized first batch of nanorods by adjusting the $\mathrm{pH}$ of fully grown "control" nanorods to $\sim 2$ with $\mathrm{HCl}$ and stirring them at $80^{\circ} \mathrm{C}$. Comparison of this first batch nanorods with control shows a blue shift in LSPR of 12-14nm (Fig. 3(c)) which was in accordance with Wang et al. (2005). This blue shift was attributed to removal of excess CTAB ( $85 \%)$ from the nanorod solution [17]. CTAB bilayer acts as stabilizing agent but is also responsible for aggregation of GNRs. Also the important point to be mind is that nanorods solution must be centrifuged after maturation in order to eliminate unreacted chemicals, Failure to which causes morphological variations in nanorods during ageing [27]. At low $\mathrm{pH}$, removal of excess CTAB also enhances stability of GNRs but by few days only. Moreover, the problem of extra third peak and reaction by-products (Fig.3 (d)) persist in this batch also.

This indicates that alteration in $\mathrm{pH}$ and temperature of nanorod dispersion after they are fully grown is not suggestive as it only removes excess CTAB but does not helps in restricting the formation of by-products. Then we thought of altering the $\mathrm{pH}$ and / or temperature 

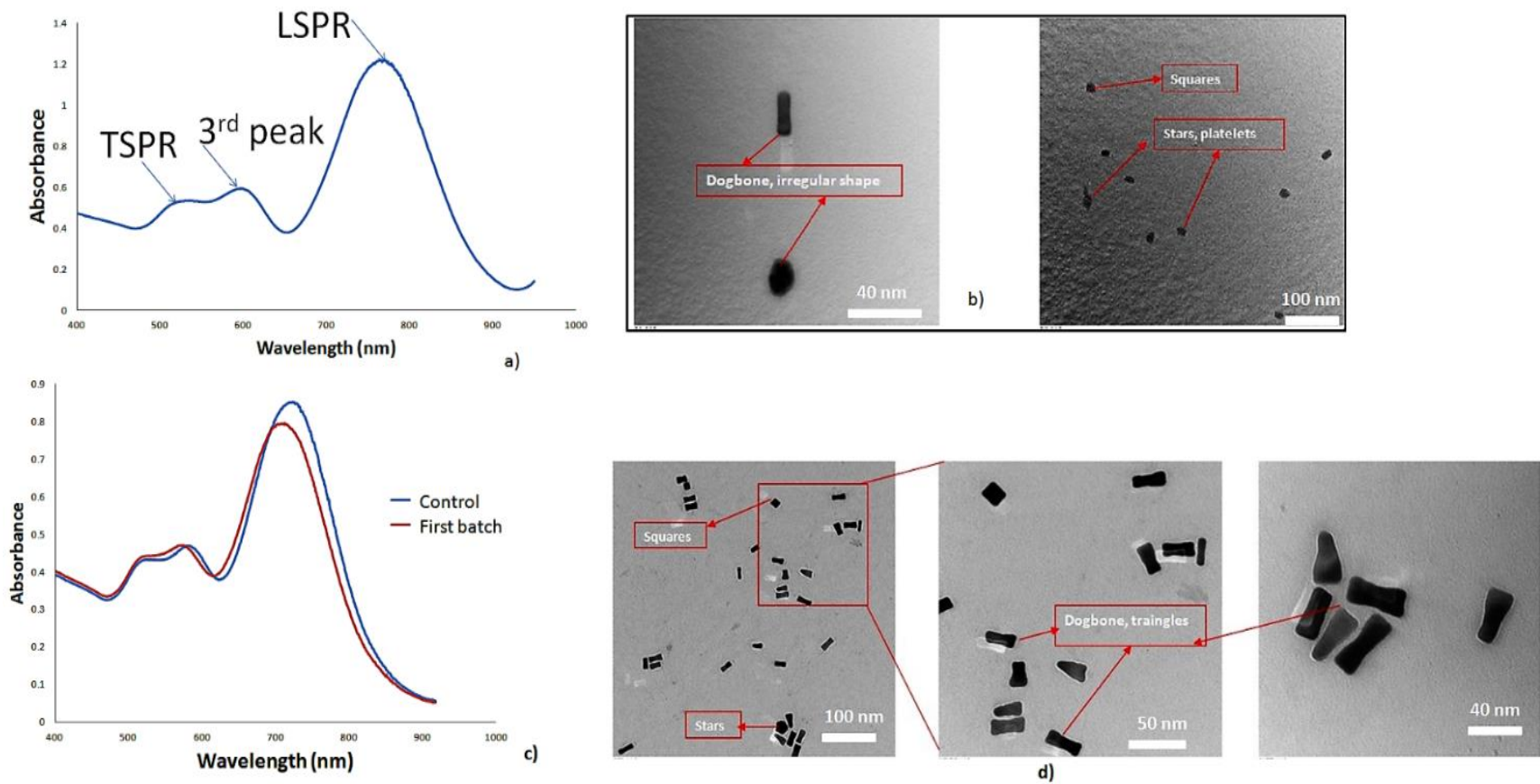

Fig. 3. Uv-Vis spectra and TEM micrographs of nanorods from control batch (a \& b), and first batch (c \& d) respectively.

immediately with addition of seed solution and allow nanorods to mature completely under altered conditions. A second batch of nanorods is synthesized at $28{ }^{\circ} \mathrm{C}$ by setting the $\mathrm{pH}$ at $\sim 2$ using $\mathrm{HCl}$. Its $\mathrm{UV}$-Vis scan shows omission of third extra peak (Fig. 4 (a)) which corroborates well with the absence of debris in TEM images (Fig. 4 (b)). These nanorods are also stable during maturation as followed from $3 \mathrm{hrs}$ to 18 hrs with minor blue shift $(10-12 \mathrm{~nm})$ in their LSPR. But we observe very slow color change (takes $2 \mathrm{hrs)}$ ) after addition of seed solution indicating very slow growth of nanorods. Moreover, the intensity of the nanorod solution at its LSPR is also significantly lower in comparison to the control (Fig. 4 (a)) indicating less concentration of nanorods in this batch. Low $\mathrm{pH}$ tends to slow down the reducing capability of weak reducing agent ascorbic acid which may not completely reduce silver ions to $\mathrm{Ag}(0)$ [28]. Therefore, altering the $\mathrm{pH}$ of solution alone does not improve the quality of nanorods. In third batch, we try to maintain the temperature of reaction medium at $80^{\circ} \mathrm{C}$ after addition of seed solution without any alteration in $\mathrm{pH}$. Reaction is faster as observed by a rapid color change of the reaction medium. These GNRs also show only two spectral peaks at $520 \mathrm{~nm}$ Transverse Surface Plasmon Resonance (TSPR) and 650 (LSPR) (Fig. 4 (c)). The intensity at LSPR was comparable or even higher than the control nanorod solution. But we recommend that the nanorod solution should not be kept long on high temperature as it continuously causes a blue shift in LSPR which goes upto $100 \mathrm{~nm}$ after overnight heating ( 18hrs) (Fig. 4(c)). TEM micrographs (Fig. 4(d)) show fattier nanorods and some of them transformed into squares as evident from their low aspect ratio (Table 1).
This is in accordance with the hypothesis proposed by Gou \& Murphy, 2005 [29] which states that the aspect ratio decreases despite increase in thickness of GNRs due to heating.

Nevertheless, these GNRs face another problem of loss due to aggregation during centrifugation. A fraction of GNRs recovered from this loss is also unstable during storage at room temperature and gradually loses its integrity. Use of low $\mathrm{pH}$ and high temperature alone although favours the formation of low aspect ratio nanorods but has associated drawbacks as discussed above. To overcome the limitations of second and third batch of nanorods and bring their positive aspects together, we thought of investigating the synergistic effect of low $\mathrm{pH}$ and high temperature, which has not been reported earlier too. In the subsequent fourth batch, nanorods are synthesized by maintaining low $\mathrm{pH} \quad(\sim 2)$ and high temperature $\left(80^{\circ} \mathrm{C}\right)$ after immediate addition of seed solution. Their dual addition has surpassed each other's limitations i.e. low $\mathrm{pH}$ has restricted excess addition of $\mathrm{Au}(0)$ on $\{110\}$ facet thereby preventing the formation of fattier /square particles as well as keeps the LSPR constant from 3-18 hrs of heating whereas high temperature has increased the reaction rate as well as improved the intensity at LSPR. Presence of two characteristic spectral peaks in UV-Vis scan (Fig. 4 (e)) and absence of any by-products in TEM micrographs (Fig. 4 (f)) speaks itself about the homogeneity of nanorod solution. The yield in terms of \%age of nanorods in comparison to other shaped particles was highest $(93 \%)$ in this batch (Table 1) and the aspect ratio of these nanorods is 2.5 . 


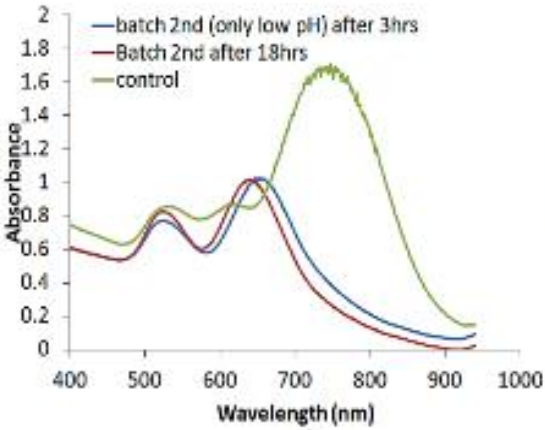

a)

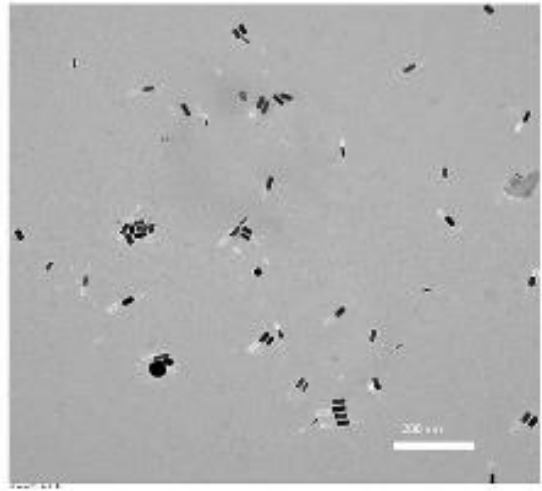

b)

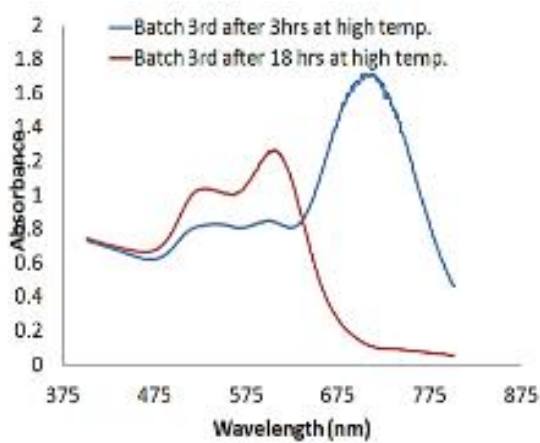

c)

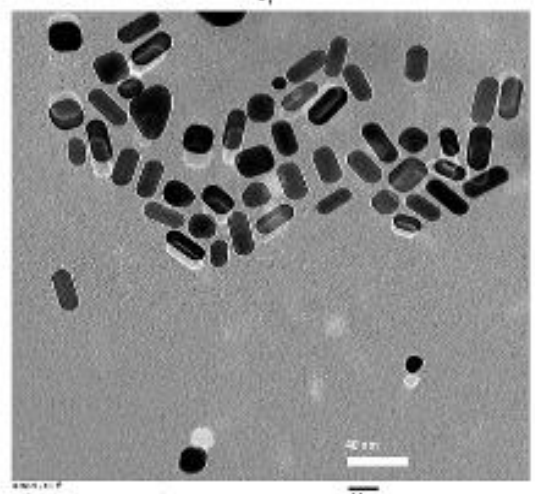

d)
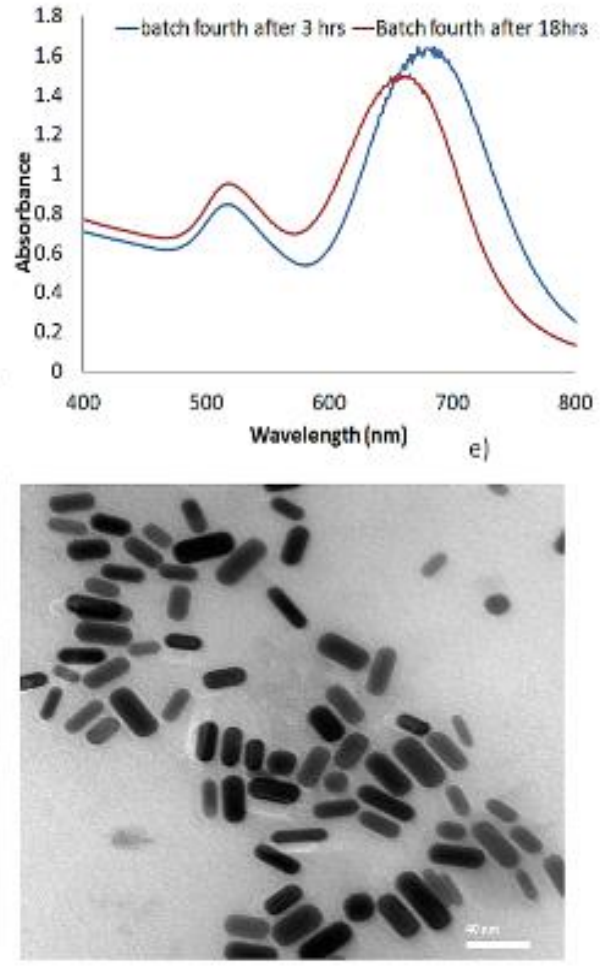

f)

Fig. 4. Uv-Vis spectra and TEM micrographs of nanorods from Second batch (a\&b), third batch (c\&d) and fourth batch (e \& f) respectively.

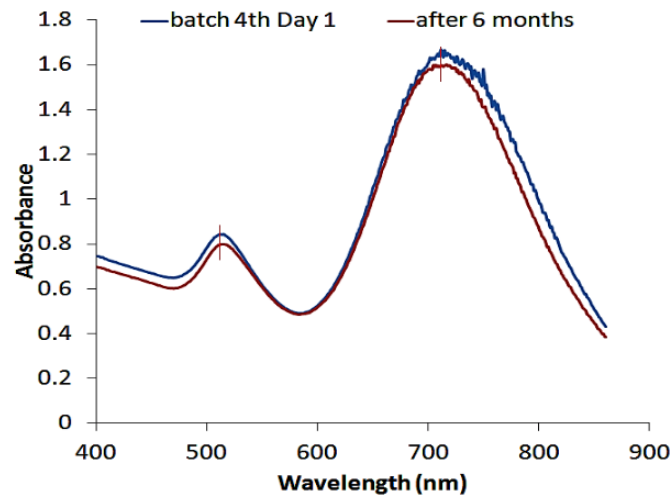

a)

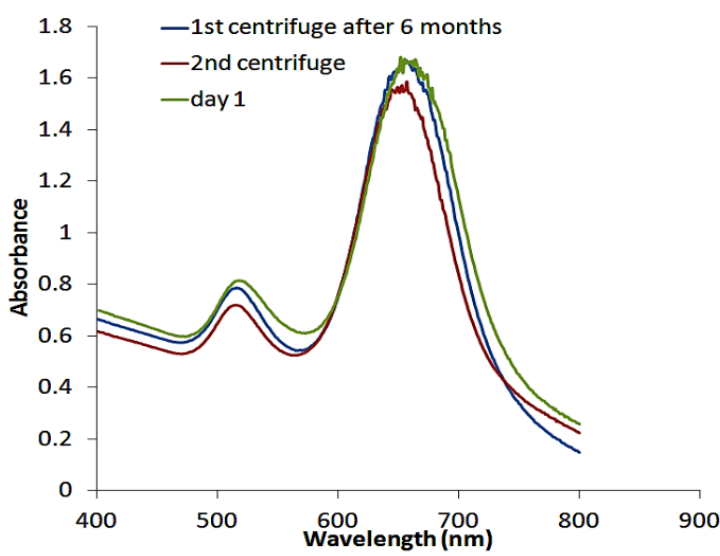

b)

Fig. 5. UV Vis spectra of nanorods from fourth batch a) comparison on day 1 and after 6 months of storage b) comparison of LSPR after two rounds of centrifugation and resuspension in miliQ water.
We also studied the stability of this batch of nanorods during ageing and storage. Comparison of LSPR after $3 \mathrm{hrs}$ and $18 \mathrm{hrs}$ of heating shows only a marginal blue shift of $12-14 \mathrm{~nm}$ indicating their stability during maturation (Fig.4 (e)). LSPR of these nanorods is also taken after six months of storage at room temperature. No change in the intensity and position of LSPR is noticed even after six months of storage at room temperature giving zero signals of aggregation (Fig.5 (a)). It proves that low aspect ratio homogeneous nanorods can be synthesized at high temperatures within $3 \mathrm{hrs}$ when combined together with low $\mathrm{pH}$. Further, it is shown that nanorods from this batch can be suspended and stored in milli-Q water even after two successive rounds of centrifugation showing greater stability as evident from their consistent LSPR (Fig.5 (b)).

Repeated centrifugation reportedly decrease $\mathrm{CTAB}$ concentration leading to a significant loss of nanorods and makes them water insoluble [21]. As for CTAB-capped GNRs to stay soluble, the amount of free CTAB in reaction mixture must stay above a critical amount and there should be a continuous dynamic exchange of CTAB between GNR surface and solution [30]. To overcome this problem, 1mM CTAB has been suggested for suspending the nanorods during repeated centrifugation. However, nanorods suspended in $\mathrm{CTAB}$ solution may not be directly used for biomedical applications due to toxicity associated with CTAB. Surface conjugation of nanorods with biomolecules requires removal and replacement of $\mathrm{CTAB}$ with 
Table 1. Comparison of yield, aspect ratio, homogeneity, and stability of gold nanorods synthesized at different reaction conditions.

\begin{tabular}{|c|c|c|c|c|c|}
\hline $\begin{array}{l}\text { Batch of } \\
\text { nanorod }\end{array}$ & $\begin{array}{l}\text { Conditions } \\
\text { of synthesis }\end{array}$ & $\begin{array}{l}\text { *Yield } \\
\%\end{array}$ & $\begin{array}{l}\text { Aspect } \\
\text { ratio* } \\
*\end{array}$ & Homogeneity & Stability \\
\hline Control & $\begin{array}{l}\text { No } \\
\text { alteration in } \\
\text { reference } \\
\text { protocol }\end{array}$ & 67.4 & 3.5 & $\begin{array}{l}\text { Appearance of } \\
\text { Three Plasmon } \\
\text { peaks instead } \\
\text { of two. } \\
\text { Presence of } \\
\text { irregular } \\
\text { shaped } \\
\text { structures like } \\
\text { dogbone } \\
\text { shaped GNRs } \\
\text { and triangles }\end{array}$ & $\begin{array}{l}\text { Aggregates } \\
\text { at room } \\
\text { temp. } \\
\text { within } \\
\text { weeks }\end{array}$ \\
\hline First & $\begin{array}{l}\text { Low } \mathrm{pH} \text { at } \\
80^{\circ} \mathrm{C} \text { with } \\
\text { stirring after } \\
\text { full } \\
\text { maturation } \\
\text { of nanorods }\end{array}$ & 68.0 & 3.4 & $\begin{array}{l}\text { Three Plasmon } \\
\text { peaks persists, } \\
\text { Blue shift in } \\
\text { LSPR in } \\
12-14 \mathrm{~nm} \text {. } \\
\text { Presence of } \\
\text { irregular } \\
\text { shaped } \\
\text { structures like } \\
\text { dogbone } \\
\text { shaped GNRs } \\
\text { and triangles }\end{array}$ & $\begin{array}{l}\text { Stable at } \\
\text { room temp. }\end{array}$ \\
\hline Second & $\begin{array}{l}\text { low } \mathrm{pH} \\
\text { alone after } \\
\text { addition of } \\
\text { seed } \\
\text { solution }\end{array}$ & 89 & 2.4 & $\begin{array}{l}\text { Appearance of } \\
\text { Two Plasmon } \\
\text { peaks, third } \\
\text { peak } \\
\text { disappeared. } \\
\text { Disappearance } \\
\text { of dogbone } \\
\text { shaped GNRs } \\
\text { and irregular } \\
\text { stars, platelets } \\
\text { or triangles }\end{array}$ & $\begin{array}{l}\text { Stable at } \\
\text { room temp. }\end{array}$ \\
\hline Third & $\begin{array}{l}\text { High temp } \\
\text { alone after } \\
\text { addition of } \\
\text { seed } \\
\text { solution }\end{array}$ & 72.6 & 2.0 & $\begin{array}{l}\text { Two } \\
\text { characteristic } \\
\text { peaks } \\
\text { Fatter } \\
\text { nanorods some } \\
\text { of them } \\
\text { transformed } \\
\text { into squares. }\end{array}$ & $\begin{array}{l}\text { Blue shift } \\
\text { of 100nm } \\
\text { in LSPR } \\
\text { after } \\
\text { overnight } \\
\text { heating } \\
\text { loss due to } \\
\text { aggregation } \\
\text { during } \\
\text { centrifugati } \\
\text { on, those } \\
\text { recovered } \\
\text { from this } \\
\text { loss were } \\
\text { also } \\
\text { unstable } \\
\text { during } \\
\text { storage. }\end{array}$ \\
\hline Fourth & $\begin{array}{l}\text { Low } \mathrm{pH} \text { and } \\
\text { High temp. }\end{array}$ & 93 & 2.5 & 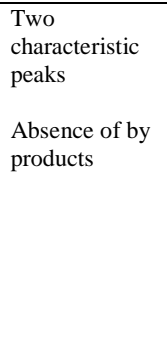 & $\begin{array}{l}\text { Stable for } \\
\text { months at } \\
\text { room temp. } \\
\text { Stable in } \\
\text { miliQ for } \\
\text { months } \\
\text { even after } \\
\text { two rounds } \\
\text { of } \\
\text { centrifugati } \\
\text { on }\end{array}$ \\
\hline
\end{tabular}

Note:

*Yield refers to fraction of rod shaped particles counted from an average of total 200 particles.

**Aspect ratio of nanorods was calculated from TEM images as well as using relationship between LSPR ( $\left.\lambda_{\mathrm{LSPR}}\right)$ of anisotropic nanomaterials and aspect ratio (R) i.e. $\lambda_{\mathrm{LSPR}}=95 \mathrm{R}+420[\mathbf{1 6}-\mathbf{1 7}]$. stabilizers like polystyrene sulfonic acid and polyethylene glycol. This makes them biocompatible and maintains their stability. To avoid this additional step, it is highly desirable to increase the stability of nanorods in absence of CTAB. It is observed that nanorods synthesized under the synergistic effect of low $\mathrm{pH}$ and high temperature is stable without any aggregation even after two rounds of centrifugation and storage in water. Excess CTAB from the dispersion is probably removed after centrifuging twice and these nanorods may prove to be minimally toxic facilitating their use for biomedical applications [31-32]. $\mathrm{HCl}$ increases stability of GNRs in months by decreasing CTAB concentration around GNR, and weakening the reducing capacity of ascorbic acid (AA) which overcomes the problem of GNR thickening during ageing or blue shifting of LSPR. AA otherwise slowly reduce the remaining gold ion concentration present in GNR solution and the $\mathrm{Au}(0)$ get deposited on GNR at the sites where it is less exposed to CTAB and makes irregular GNRs. Heating on the other hand helps in removing debris, dog-bone shaped GNRs by preventing the binding of CTAB on laterally growing crystals so that uniform growth of GNRs can occur.

\section{Conclusion}

We present an improved and simpler approach to synthesize more homogeneous, and highly stable gold nanorods. Use of low $\mathrm{pH}$ and high temperature immediately with addition of seed solution prevents the formation of debris or unwanted structures. In addition, it allows faster synthesis of nanorods i.e. within $3 \mathrm{hrs}$ in comparison to overnight incubation of nanorods in well-established protocols. These nanorods are stable for months and their stability remains intact even when they are stored in milli-Q water after removal of excess CTAB by two rounds of centrifugation. Due to low CTAB, these homogeneous and highly stable nanorods present immense potential for various biomedical applications.

\section{Acknowledgements}

We greatfully acknowledge the TEM facility of CIL, SAIF, Panjab University Chandigarh for TEM characterization of gold nanorod samples.

\section{Author's contributions}

Conceived the plan: SS, SN; Performed the expeirments: NK; Data analysis: SS, SN; Wrote the paper: NK, SN. Authors have no competing financial interests.

\section{References}

1. Sau, T.K.; Murphy, C.J.; J. Am. Chem. Soc., 2004, 126, 8648.

2. Navarro, J.R.G.; Manchon, D.; Lerouge, F.; Blanchard, N.P.; Marotte, S.; Leverrier, Y.; Marvel, J.; Chaput, F.; Micouin, G.; Gabudean, A.-M.; Mosset, A.; Cottancin, E.; Baldeck, P.L.; Kamada, K.; Parola, S.; Nanotechnology, 2012, 23, 465602.

3. Pham, T.; Jackson, J.B.; Halas, N.J.; Lee, T.R.; Langmuir, 2002, $18,4915$.

4. Daniel, M.C.; Astruc D. Chem Rev. 2004,104, 293.

5. Guo, Y.J.; Sun, G.M.; Zhang, L.; Tang, Y.J.; Luo, J.J.; Yang, P.H.; Sensors Actuators B Chem., 2014,19, 741. 
6. Nikoobakht, B.; Sayed, A-El.;Chem Mater., 2003, 16, 1957.

7. Van Der Zande, B.M.I.; Böhmer, M.R.; Fokkink, L.G.J.; Schönenberger, C.; Langmuir, 2000, 16, 451.

8. Kim, F.; Kwan, S.; Akana, J.; Yang, P.; J. Am. Chem. Soc., 2001,123, 4360 .

9. Chang, S-S.; Lee, C-L.; Wang, C.R.C.; J. Phys. Chem. B., 1997, 101,6661 .

10. Jana, N.R.; Gearheart, L.; Murphy, C.J.; J. Phys. Chem. B. 2001,105, 4065 .

11. Busbee, B,D.; Obare, S.O.; Murphy, C.J.; Advanced materials. 2003, 15, 414 .

12. Feng, L.; Xuan, Z.; Ma, J.; Chen, J.; Cui, D.; Su, C.; Guo, J.; Zhang, Y.; J. Exp. Nanosci., 2015, 10, 258.

13. Sau, T.K.; Murphy, C.J.; Langmuir, 2004, 20, 6414.

14. Jiang, X.C.; Pileni, M.P.; Colloids Surf. A., 2007, 295, 228.

15. Gao, J.; Bender, C.M.; Murphy, C.J.; Langmuir., 2003, 19, 9065.

16. Koeppl, S.; Solenthaler, C.; Caseri, W.; Spolenak, R.; J. Nanomater., 2011, 2011, 515049.

17. Wang, C.; Wang, T.; Ma, Z.; Su, Z.; Nanotechnology, 2005, 16, 2555.

18. Wang, Z.; Zong, S.; Yang, J.; Song, C.; Li, J.; Cui, Y.; Biosens. Bioelectron., 2010, 26, 241.

19. Altansukh, B.; Yao, J.; Wang, D.; J. Nanoscience. Nanotech., 2008, 8,1 .

20. Jana, N.R.; Small, 2005, 1, 875 .

21. Perez-Juste, J.; Rodriguez-Gonzalez, B.; Mulvaney, P.; LizMarzan, L.M.; Adv. Funct. Mater. 2005, 15, 1065.

22. Zijlstra, P.; Bullen, C.; Chon, J.W.M.; Gu, M.; J. Phy. Chem. B., 2006,110, 19315.

23. Pak, H.J.; Ah, C.S.; Kim, W-J.; Choi, K-P.; Yuna, W.S.; J. Vac. Sci. Technol. A., 2006, 24, 1323.

24. Park, K. "Synthesis, Characterization, and Self -Assembly of Size Tunable Gold Nanorods" In, Doctor of Philosophy, School of Polymer, Textile and Fiber Engineering, Georgia Institute of Technology, Atlanta, USA; 2006

25. Becker, R.; Liedberg, B.; Kail, P.O.; J. Colloid. Interf. Sci., 2010, 343, 25 .

26. Murphy, C.J.; Thompson, L.B.; Chernak, D.J.; Yang, J.A.; Sivapalan, S.T.; Boulos, S.P.; Huang, J.; Alkilany, A.M.; Sisco, P.N.; Curr. Opin. Colloid Interface Sci., 2011, 16, 128.

27. Canonico-May, S.A.; Beavers, K.R.; Melvin, M.J.; Alkilany, A.M.; Duvall, C.L.; Stone, J.W.; J. Colloid. Interface. Sci., 2016, 463, 229.

28. Oza, G.; Pandey, S.; Vishwanathan, M.; Kesarkar, R.; Sharon, M.; Sharon, M.; Adv. Appl. Sci. Res., 2012, 3,1027.

29. Gou, L.; Murphy, C.J.; Chem. Mater., 2005,17, 3668

30. Orendorff, C.J.; Alam, T.M.; Sasaki, D.Y.; Bunker, B.C.; Voigt, J.A.; ACS Nano, 2009, 3, 971.

31. Cortesi, R.; Esposito, E.; Menegatti, E.; Gambari, R.; Nastruzzi, C.; Int. J. Pharm., 1996, 139, 69.

32. Takahashi, H.; Niidome, Y.; Niidome, T.; Kaneko, K.; Kawasaki, H.; Yamada, S.; Langmuir, 2006, 22, 2. 